\title{
Prioritizing the performance of civil development projects in governmental administration agencies, using gray relational analysis (GRA) and TOPSIS approach
}

\author{
Ali Mohammadi ${ }^{*}$, Payam Shojaei ${ }^{\mathrm{b}}$, Bahareh Kaydanc and Zahra Akbaric
}

${ }^{a}$ Professor of management, Department of Management, Shiraz University, Shiraz, Iran

${ }^{b}$ Assistant Prof., Department of Management, Shiraz University, Shiraz, Iran

${ }^{c}$ Masters Student, Department of Management, Shiraz University, Shiraz, Iran

\section{A B S T R A C T}

A key indicator to evaluate the success of an organization is the degree of meeting specific civil project goals based on a predetermined schedule. Therefore, the main purpose of this paper is to evaluate the performance of governmental administration agencies based on realization of civil project goals. In this paper, the information published by the President Deputy of Strategic Planning and Control, that publishes an annual report of evaluation indicators for national civil development projects, are used to evaluate and prioritize the major and non-major governmental agencies. Also, the Gray Relational Analysis (GRA) and the TOPSIS method are employed to analyze the data. The results indicate that using the GRA method, Supreme Council of Seminary and using the TOPSIS method, The Ministry of Labor and Social Affaires have gained the highest ranking.

\section{Introduction}

One of the main tasks of the President Deputy of Strategic Planning and Control is associated with supervising the civil operations and reporting on the progress of the projects funded by the governmental civil and current credits. The supervision reports of national development projects are prepared annually, based on the operations description agreements, in order to inform the authorities of the governmental administration agencies, about the performance of agencies in executing the national civil development projects. In order to evaluate the operations and their results and comparing them with the specified goals in the country's civil and budget regulations, there are specific instructions, which frequently inspect the designs and programs of the administration agencies and the results of these inspections notify the authorities about these agencies. The supervision information gained from the evaluation of the governor's experts is used to set the reports as well as the information

* Corresponding author. Tel \& Fax: +987136276372

E-mail address: pshojaei@shirazu.ac.ir (P. Shojaei)

(C) 2016 Growing Science Ltd. All rights reserved. doi: $10.5267 /$ j.dsl.2016.5.003 
from the latest agreements exchanged in the President Deputy of Strategic Planning and Control. In this regard, the Plan and Budget Organization must present a six-month report to the President including the progress of operations, operational issues and activities as well as specific proposals to resolve the issues (President Deputy of Strategic Planning and Control, 2014).

In this article, according to the information available, the performance evaluation of major and nonmajor governmental administration agencies is taken into consideration. According to the Department of Planning report, major governmental administration agencies include: Ministry of Science, Research and Technology, Ministry of Education, Ministry of Sports and Youth, Ministry of Health and Medical Education, Ministry of Housing and Urban Development, Ministry of Energy, Ministry of Industries and Mine, Ministry of Transportation and Ministry of Agriculture Jihad that their approved credits in 2012 (from the place of public revenues and other resources) have been more than 6500 billion Rials (President Deputy of Strategic Planning and Control, 2014). In many papers, analytical models for conflict management are recommended. Among the multiple approaches to conflict management, Multi Criteria Decision-Making (MCDM) is very common. Multi Criteria Decision Making process can be a complex and dynamic process also at the engineering and managerial level. The objectives are defined at the managerial level and the final answer will be chosen. The nature of the multi-criteria decision focuses on the same managerial level (Opricovic, 1998).

Multi-criteria optimization is a process that determines the best solution justified according to the predefined criteria (with different effects). More methods of Multi-criteria are needed to define the weights for each criterion quantitatively, to assess the relative importance of different criteria. Methods such as multi-criteria analysis of TOPSIS and GRA include the techniques of some criteria that in a complex system are used to prioritize alternatives. The purpose of this article is to prioritize the country's administration agencies, based on the data published in the national reports of the development projects in 2012 With GRA and TOPSIS techniques.

The theoretical framework and research backgrounds are discussed in section 2 . The third section presents the research method and relationship analysis of the two methods and a brief description of the GRA and TOPSIS are presented. In the fourth section, the final results of the analysis are discussed. Finally, the last section discusses the conclusions and addresses future research.

\section{Background Research}

\subsection{National Civil development projects and Performance Prioritizing Indicators}

Development and civil activities of every country are normally divided into four departments, Public Affairs Department, Defense and Security Affairs, Economic Affairs and Social and Cultural Affairs. Each of these affaires contains one or more chapters that encompass various programs. In other words, development plans of a similar type of operation and goals are placed in one category, the formation of programs and a collection of several programs are called a chapter and a collection of several chapters make the affairs. In each chapter, items such as general characteristics, physical progress and execution status and the financial status of projects under execution are presented. The performance of governmental administration agencies, including the ministries, their affiliate companies, government institutions and organizations and non-governmental public organizations that execute the projects are presented according to their main administration agency. The function of each main administration agency represents the status of the agency and related institutions and companies. Civil development projects are classified into constructions, development, equipment, repair, design studies, fundamental studies, detailed design, supervision, services and obligations projects (President Deputy of Strategic Planning and Control, 2014). Due to this division of the national civil development projects $5.54 \%$ has been construction projects (3620 project of a total of 6642). In the report monitoring national civil 
development projects in 2012, the following indicators were used in order to rank the governmental administration agencies:

1- The Percentage of the Projects Accomplishment Index (PPA): The index, which is calculated from the projects visited, is obtained from the Eq. (1).

$$
P P A=\frac{\text { Number of Completed Projects }}{\text { Number of Projects to be Completed }} \times 100
$$

2- The Goal Attainment to Resource Attainment Ratio Index (GARAR): This index is equal to the ratio of the index of annual payments to achieve the goals of the treasury approved the credit percentage. Indicators of achievement are calculated from the relationship of annual goals Eq. (2), So that $n$ indicates the number of the project.

GARAR $=\frac{\sum_{i=1}^{n}(\text { Approved Credit of 2012)(The Reporetd Physical Progress in 2012) }}{\sum_{i=1}^{n}(\text { Approved Credit of 2012)(The Expected Physical Progress in 2012) }}$

3- Project Conduct Duration Index (PCD): The index for the Execution term is obtained from the Eq. (3) that on witch:

$$
P C D=-36.182 \operatorname{Ln}\left(\frac{t_{i}}{t_{m}}\right)+50
$$

In which:

$t_{i}=$ The execution time for completed projects in 2012 .

$t_{m}=$ The average execution time for completed projects over the past years.

4- The Work Referring Method Index (WRM): The score of work referring method for the percentage of public tender projects (PTP) is 100 and for the limited tender projects (LTP) is 70, so that:

$$
W R M=(\text { Percentage of PTP })+(\text { Percentage of LTP }) \times 0.7
$$

5- The Causes of the delay Index (CD): This indicator is also defined as follows,

$$
C D=-670.16\left(\frac{a}{b}\right)^{4}+1509.3\left(\frac{a}{b}\right)^{3}-952.51\left(\frac{a}{b}\right)^{2}+13.695\left(\frac{a}{b}\right)+99.441
$$

$a=$ The number of delays caused by the deficiency of the executive agency.

$b=$ The number of supervised executive projects in the year 2012

Delays which the governmental administration agencies have somehow caused include: land possession, funding, design consultanting, and supervisor consultanting, contractor and executive administration. Items related to the deficiency of the administration agency directly and other cases are indirectly linked to the performance of the administration agency.

6- The Conduct Quality Index (CQ): The score of execution quality indicator of civil development projects under execution and completed projects are calculated regarding technical workers, the quality of the materials, supervisor consulting experts, the contractor experts, documenting, quality controls in stages of the execution, workshop and machinery equipment, maintenance of materials and standards, the criteria and guidelines which are the basis of the related questionnaire. The values of this indicator for the governmental administration agencies are given in Table 1.

\subsection{Related Research}

Several studies have been accomplished in conjunction with the methods of measurement and performance evaluation. Ye and Tiong (2000) used the method of current value based on risk, to evaluate the project financing of the macro-infrastructural in Singapore. They, after identifying the 
strengths and weaknesses of different methods and the combination of two techniques, weighted average cost of capital and risk and used the secondary income to analyze the project. In another study, Enea and Piazza (2004) developed the method for the projects selection with using fuzzy hierarchy analysis method. They are using all the information possible and put them in the form of a decision addressed to limit analysis and financial and qualitative factors were also considered. Tuysuz and Kahraman (2006) applied a process of hierarchical analysis to evaluate information and the risk of the technology of projects, and criteria such as managing relationships, resource planning, human resources and technology were considered. Tzeng and Teng (2007) developed a model for project selection in capital investment and transportation with fuzzy multi-objective decision, using an efficient algorithm of three forms of independent investment projects, where the evaluation of complementary and alternative was assessed and a multi-objective integer programming was used to solve the resulted model. For risk assessment in projects of construction industry, Ebrahimnejad et al. (2008) offered a model, the criteria and indicators for the analysis presented then, by using the method of fuzzy TOPSIS and Linmap fuzzy for risk assessment. Pophali et al. (2011) used a combined method of Analytical Hierarchy Process (AHP) and grey relational algorithm (GRA) for optimal selection of full scale tannery treatment plants in India. They reported that the AHP and GRA were powerful tools that can be used for selection implementation of appropriate wastewater treatment technology. In another study, to evaluate the projects of provincial gas pipeline companies, Mohamadi and Shojaei (2011), employed a combined approach of FAHP and GRA for pipeline selection. For this purpose on the basis of sustainable development indicators technical criteria, financial, economic and social were considered. In another research in order to evaluate the company's gas projects in Fars province of Iran, Mohamadi et al. (2012) employed ecological approaches and studied the ecological risks in the macro projects. In order to evaluate the competitiveness of Chinese high-tech industry in 2011, Wang and Wang (2014) employed the improved TOPSIS technique and compared the results with the traditional TOPSIS method. The improved TOPSIS method has an improved relative closeness which is invariant after non-singular linear transformation.

In a study accomplished by Oztaysi (2014), the selection of Content Management System (CMS) among available alternatives was regarded as a multi criteria decision making problem. For this matter, AHP integrated Gray-TOPSIS method was proposed and applied in a Turkish foreign trade company. The weights of the criteria were determined by AHP method and the alternatives were evaluated by Gray-TOPSIS. Due to the uncertainties, gray numbers were used for evaluations of the alternatives. One at a time sensitivity analysis is also provided in order to monitor the robustness of the method to the changes in the weights of evaluation criteria. In order to evaluate the performance of different projects in a construction company Zavadskas et al. (2014) analyzed the problem of project performance indicators selection. Then the aggregated project's performance criterion was determined by applying the methods of multi-criteria analysis and logarithmic normalization method and AHP was applied. Results show that by using the aggregated indicators it is easy to compare the projects, the received impartial information is useful for strategic planning, quality management, for solving the tasks of resource allocation, motivational project evaluation.

In a study executed by Wang et al. (2016) in an IC packaging company, a hybrid MCDM method was presented combining simple additive weighting (SAW), techniques for order preference by similarity to an ideal solution (TOPSIS) and gray relational analysis (GRA) techniques. In this study an experimental design technique was applied to assign attribute weights and then combined different MCDM evaluation methods to construct the hybrid decision-making model. The results indicated that the ranking results agreed according to multiple MCDM methods. Uygun and Dede (2016) developed a model based on integrated fuzzy MCDM methods for evaluating Green Supply Chain Management (GSCM) performance of companies in terms of green design, green purchasing, green transformation, green logistics and reverse logistics. In this study, the cause and effect interrelationship amongst GSCM dimensions was figured out using fuzzy DEMATEL method. Then, based on this interrelationship, Fuzzy ANP method was implemented for calculating the weights of the related criteria. Finally, fuzzy 
TOPSIS method was applied by using the weights obtained from fuzzy ANP method, for evaluating and ranking the GSCM performance of alternative companies. In another study applied to evaluate the performance of partnership between a logging company and a sawmill in British Columbia by Piltan and Sowlati (2016), a multi-criteria decision support model was developed to evaluate the performance of an ongoing partnership in different periods based on the measures associated with the drivers for entering into the partnership. Interpretive Structural Modeling (ISM), Analytical Network Process (ANP) and Fuzzy Logic (FL) were used in order to address the interdependency, the importance of, and the uncertainty in performance measures, respectively. The rankings from the model were compared to the ones estimated by the managers, and the results showed that the rankings are compatible. Reviews of the research are generally taken and the research carried out within the specific form indicating the most of the measures taken to evaluate the projects based on the level of wisdom and rankings have been on the basis and less detailed technical indicators in terms of their evaluations. Evidently, executing such an approach especially at the macro level, in order to determine the position of each of the governmental administration agencies, can help politicians and decision makers in capital budgeting, and the appropriate cost and time management.

\section{Research Methodology}

In order to evaluate the performance of national civil operations, six main and result-oriented indexes are employed which are: the percentage of completion, the execution quality, the ratio of achieved goals to attained resources, the time of execution, the method of work referring and the causes of delay. The scope of the calculated rates, for each of the indicators was from zero to 100 . In the case of indicators such as the percentage completion and the ratio of achieved goals to attained resources it is possible that some of the governmental administration agencies become greater than 100 percent, 100 points for evaluation against the ceiling also are considered. The values of these indicators are given for the governmental administration agencies on Table 1. This table is used as the decision matrix for TOPSIS and the (GRA).

\subsection{Techniques for Order Preference by Similarity to an Ideal Solution (TOPSIS)}

TOPSIS is a multiple criteria decision making method which is initially proposed by Hwang and Yoon (1981). In this method, $M$ alternatives by $N$ index are evaluated. The method is originated from the idea that the optimal solution ought to have the shortest distance from the positive ideal solution and the farthest from the negative ideal solution. A solution is determined as a positive ideal solution if it maximizes the benefit criteria or minimizes the cost criteria. In addition, the solution, which maximizes the cost criteria or minimizes the benefit criteria is called the negative ideal solution (Oztaysi, 2014). In other words, while ranking alternatives in TOPSIS method, alternatives with the greatest similarity to the ideal solution gain the highest rank. The target interval between the two criteria is shown, as an example in Fig. 1. A + and A- respectively are the solution of the positive and negative ideals. Alternative A1 has the shorter interval to the ideal solution and more distance to the negative ideal solution.

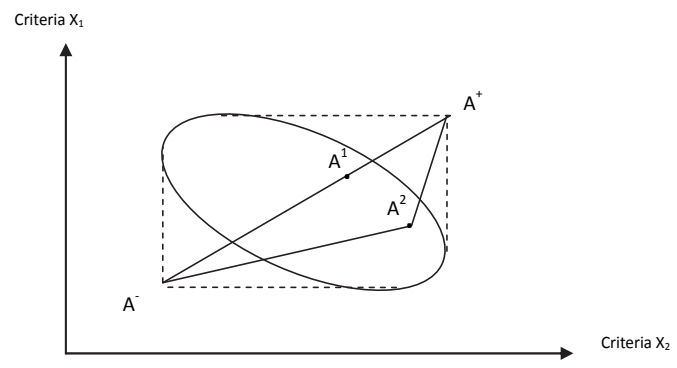

Fig. 1. The target interval is the ideal solution between two criteria: positive and negative 
In this method, in addition to taking into account the distance of an alternative the ideal point of $A_{i}$, its distance from the negative ideal point is considered. It is assumed that the desirability of each indicator is increasing/reducing steadily. Problem solving with this method needs the following six steps:

The first step: the quantification and normalization of decision matrix $(N)$ :

To normalize the decision matrix, for each element the bellow equation is used:

$$
n_{i j}=\frac{a_{i j}}{\sqrt{\sum_{i=1}^{m} a_{i j}^{2}}}
$$

Step two: Obtaining the weighted normalized matrix (V):

In order to calculate the weighted normalized matrix, the normalized matrix $(N)$ is multiplied by $\mathrm{W}_{\mathrm{n} \times \mathrm{n}}$ which is a square matrix and its diametrical elements are the weights of the indicators and the rest of the elements are 0 .

$$
V=N \times W_{n \times n}
$$

Step three: obtaining a positive ideal $V_{j}^{+}$and a negative ideal $V_{j}^{-}$for each indicator.

Step four: determining the distance between each alternative and its positive and negative ideals.

$$
\begin{aligned}
& d_{i}^{+}=\sqrt{\sum_{j=1}^{n}\left(v_{i j}-v_{j}^{+}\right)^{2}} \quad i=1,2, \ldots, m \\
& d_{i}^{-}=\sqrt{\sum_{j=1}^{n}\left(v_{i j}-v_{j}^{-}\right)^{2}} \quad i=1,2, \ldots, m
\end{aligned}
$$

Step five: determining the relative proximity of each alternative to the ideal solution.

$$
C L_{i}^{*}=\frac{d_{i}^{-}}{d_{i}^{-}+d_{i}^{+}}
$$

Step six: ranking the alternatives:

The alternative with the greater CL is the best alternative to choose.

\subsection{Gray Relational Analysis (GRA)}

The Gray system theory was formulated by Ju-long Deng (1982). A white system is defined when the internal message, such as architecture, operation mechanism, system characteristics and parameters, are known, completely. On the contrary, if one cannot reach any information and characteristics about the system, then it is a black system. Gray space is thus a system defined between the white and black systems (Lu et al., 2008). The gray system theory is implemented to solve obscure problems discrete data and incomplete information. This theory uses relatively less information with variability in the criteria and generates various and satisfactory output. Just like fuzzy theory, the gray theory is an effective mathematical model for solving uncertain problems (Deng, 1982). This theory, also known as Gray Relational Analysis (GRA) is implemented for many problems as multi-criteria decision making. GRA is a part of Gray Theory and is implemented to solve the problems with complex relationships among the factors and the variables. In GRA, two categories of data called "data series" 
are implemented to create relations in a gray system. The first data series are called "reference sequence" (Eq.(11)) and the correlation of these series are examined with others series called "comparatives sequence" (Eq. (12)).

$$
x_{0}=\left(x_{0}(1), x_{0}(2), \ldots, x_{0}(n)\right)
$$

A series of data is about features and specifications of the system and a series of related factors on the following basis.

$$
x_{0}=\left(x_{0}(1), x_{0}(2), \ldots, x_{0}(n)\right)
$$

In this case the actual numbers for the Eq. (13) will represent the relationship between gray ratings.

$$
\gamma\left(x_{0}, x_{i}\right)=\frac{1}{n} \sum_{k=1}^{n} \gamma\left(x_{0}(k), x_{i}(k)\right)
$$

and the coefficient $\zeta \in(0.1)$ of the gray relation is obtained from Eq. (14)

$$
\gamma\left(x_{0}(k), x_{i}(k)\right)=\frac{\min _{i} \min _{k} \Delta_{i}(k)+\zeta \max _{i} \max _{k} \Delta_{i}(k)}{\Delta_{i}(k)+\zeta \max _{i} \max _{k} \Delta_{i}(k)} .
$$

The coefficient $\zeta$ is a gray relationship parameter that is called the Distinguishing Coefficient and is always a value between 0 and 1 . In most cases, its value is considered equal to 0.5 that reflects the competitive environment. In the case of $\zeta=0$, it means the impact of the environment is ignored and in the case of $\zeta=1$ the environment is considered completely and perfectly effective (Tseng et al., 2003). As $\zeta$ changes, the extent between the references will be distinguished. If $\zeta=1$ the coefficient of gray relationship reaches its minimum value and if $\zeta=0$ the coefficient of gray relationship will get its maximum value (Huang et al., 2007)

In the above equation $\Delta_{i}(k)=\left|x_{0}^{\prime}(k)-x_{i}^{\prime}(k)\right|$ which represents the difference between the data sequences compared to each other. For each index, the reference sequence represents the best functional that is obtainable among of comparative sequence. So, if a comparative sequence for an alternative has the highest ranking of a gray relationship with reference sequence, this means that these comparative sequences have the highest similarities with reference sequence and so this alternative is the best choice (Mohamadi et al., 2011).

The numbers must be normalized before calculating the gray relation and for this purpose it is necessary that the nature of each of the identified criteria and the desirability of them as being more or less be reviewed.

$$
\begin{aligned}
x_{i}^{*}(k) & =\frac{x_{i}(k)-\min _{k} x_{i}(k)}{\max _{k} x_{i}(k)-\min _{k} x_{i}(k)} \\
x_{i}^{*}(k) & =\frac{\max _{k} x_{i}(k)-x_{i}(k)}{\max _{k} x_{i}(k)-\min _{k} x_{i}(k)}
\end{aligned}
$$

\subsection{Shannon Entropy}

Entropy is a very important concept in the social sciences, physics, and information theory and when the data of a decision matrix is completely specified, this method can be used to evaluate the weights. In information theory, Entropy is uncertainty measure and is defined with the specified probability distribution $\mathrm{P}_{\mathrm{i}}$. If $m$ is the number of alternatives and $n$ is the number of indicators, the weights of the indicators are obtained through the following steps: 
First step: The probability distribution is calculated through the Eq.17

$$
P_{i j}=\frac{a_{i j}}{\sum_{i=1}^{m} a_{i j}}
$$

Second step: calculate the value of entropy in which $k=\frac{1}{\ln m}$.

$$
E_{j}=-k \sum_{i=1}^{m} P_{i j} \ln P_{i j}
$$

Third step: the value of the uncertainty is obtained from the Eq. (19)

$$
d_{j}=1-E_{j}
$$

Fourth step: the index weights will be calculate through the Eq. (20)

$$
w_{j}=\frac{d_{j}}{\sum_{i=1}^{n} d_{j}}
$$

\section{Results}

In order to prioritize the governmental administration agencies, first, the Shannon entropy method is applied to obtain the weight of each of the 6 indicators for performance evaluation given by Eq. (2).

\begin{tabular}{|c|c|c|c|c|c|c|}
\hline Governmental Administration Agencies & PPA & GARAR & PCD & WRM & $\mathrm{CD}$ & $\mathrm{CQ}$ \\
\hline Ministry of Industries and Mine & 67.1 & 142.5 & 103.7 & 101.2 & 62.0 & 91.9 \\
\hline Ministry of Agriculture Jihad & 71.2 & 121.0 & 75.2 & 97.3 & 101.4 & 90.3 \\
\hline Ministry of Sports and Youth & 100.0 & 95.6 & 57.0 & 107.4 & 91.0 & 86.8 \\
\hline Ministry of Interior & 74.1 & 114.5 & 45.5 & 73.2 & 85.8 & 94.1 \\
\hline Ministry of Science, Research and Technology & 74.7 & 114.6 & 56.0 & 92.6 & 68.5 & 87.7 \\
\hline Ministry of Health and Medical Education & 66.8 & 143.0 & 53.6 & 81.3 & 76.9 & 88.5 \\
\hline Ministry of Housing and Urban Development & 60.3 & 91.0 & 55.4 & 100.0 & 70.5 & 92.1 \\
\hline Ministry of Roads and Transportation & 41.4 & 126.3 & 56.3 & 100.4 & 75.0 & 89.4 \\
\hline Ministry of Education & 54.1 & 86.4 & 51.4 & 90.6 & 108.9 & 86.7 \\
\hline Ministry of Energy & 32.6 & 76.6 & 55.5 & 102.5 & 83.5 & 95.8 \\
\hline Ministry of Petroleum & 82.2 & 54.2 & 78.6 & 99.1 & 103.4 & 92.9 \\
\hline President Deputy Strategic Planning and Control & 68.8 & 161.3 & 44.3 & 55.5 & 109.4 & 95.3 \\
\hline Ministry of Information and Communications Technology & 44.1 & 117.2 & 58.0 & 87.5 & 109.4 & 89.9 \\
\hline Ministry of Welfare and Social Security & 110.0 & 126.5 & 10.0 & 52.5 & 109.4 & 76.7 \\
\hline Ministry of Labor and Social Affairs & 73.6 & 184.1 & 25.1 & 105.4 & 68.5 & 84.6 \\
\hline Supreme Council of Seminary & 110.0 & 132.3 & 10.0 & 110.0 & 42.0 & 80.7 \\
\hline Ministry of Culture and Islamic Guidance & 65.6 & 74.2 & 62.0 & 76.4 & 78.1 & 84.9 \\
\hline Ministry of Economic Affairs and Finance & 50.0 & 212.5 & 50.2 & 61.3 & 87.6 & 77.7 \\
\hline Islamic Republic of Iran Broadcasting & 37.3 & 85.7 & 39.1 & 71.2 & 101.7 & 89.3 \\
\hline Housing Foundation of Islamic Revolution & 20.0 & 114.4 & 10.0 & 76.7 & 109.4 & 95.4 \\
\hline Ministry of Justice & 73.7 & 57.5 & 44.8 & 93.2 & 65.1 & 84.9 \\
\hline Islamic Development Organization & 70.0 & 128.1 & 10.0 & 10.0 & 109.4 & 76.5 \\
\hline Cultural Heritage, Handcrafts and Tourism Organization & 44.0 & 124.4 & 10.0 & 60.2 & 81.1 & 85.7 \\
\hline Law Enforcement Force & 55.3 & 85.3 & 33.6 & 99.8 & 39.0 & 78.7 \\
\hline Ministry of Foreign Affairs & 17.7 & 27.4 & 20.3 & 68.3 & 109.4 & 110.0 \\
\hline Foundation of Martyrs and Veterans Affairs & 35.0 & 157.6 & 10.0 & 66.7 & 109.4 & 10.0 \\
\hline
\end{tabular}

\section{Table 1}

The results of the performance evaluation of the major and non-major governmental administration agencies

\section{Table 2}

The weight of the administration agencies' index

\begin{tabular}{cccccc}
\hline PPA & GARAR & PCD & WRM & CD & CQ \\
\hline 0.184 & 0.156 & 0.409 & 0.109 & 0.075 & 0.067 \\
\hline
\end{tabular}

These weights will be used to rank the performance of governmental administration agencies in TOPSIS and GRA methods. It should be noted that PCD and CD are negative aspects and other indicators are positive aspects. 


\subsection{Ranking Administration Agencies using TOPSIS}

As mentioned in the previous section, Table 1 is considered as the decision matrix. So the weighted normalized matrix is given in Table 3 . According to the values of the Table 3, positive and negative ideal vectors are given in Table 4.

\section{Table 3}

The weighted normalized matrix of governmental administration agencies

\begin{tabular}{|c|c|c|c|c|c|c|}
\hline Governmental Administration Agencies & PPA & GARAR & PCD & WRM & $\mathrm{CD}$ & CQ \\
\hline Ministry of Industries and Mine & 2.465 & 5.155 & 17.403 & 2.567 & 0.633 & 1.278 \\
\hline Ministry of Agriculture Jihad & 2.775 & 3.717 & 9.152 & 2.373 & 1.694 & 1.234 \\
\hline Ministry of Sports and Youth & 5.475 & 2.32 & 5.258 & 2.891 & 1.364 & 1.14 \\
\hline Ministry of Interior & 3.006 & 3.328 & 3.35 & 1.343 & 1.213 & 1.34 \\
\hline Ministry of Science, Research and Technology & 3.055 & 3.334 & 5.075 & 2.149 & 0.773 & 1.164 \\
\hline Ministry of Health and Medical Education & 2.443 & 5.191 & 4.649 & 1.657 & 0.974 & 1.185 \\
\hline Ministry of Housing and Urban Development & 1.991 & 2.102 & 4.967 & 2.506 & 0.819 & 1.283 \\
\hline Ministry of Roads and Transportation & 0.938 & 4.05 & 5.13 & 2.526 & 0.927 & 1.209 \\
\hline Ministry of Education & 1.602 & 1.895 & 4.276 & 2.057 & 1.954 & 1.137 \\
\hline Ministry of Energy & 0.582 & 1.49 & 4.985 & 2.633 & 1.149 & 1.388 \\
\hline Ministry of Petroleum & 3.699 & 0.746 & 9.998 & 2.461 & 1.762 & 1.306 \\
\hline President Deputy Strategic Planning and Control & 2.591 & 6.605 & 3.176 & 0.772 & 1.972 & 1.374 \\
\hline Ministry of Information and Communications Technology & 1.065 & 3.487 & 5.444 & 1.919 & 1.972 & 1.223 \\
\hline Ministry of Welfare and Social Security & 6.624 & 4.063 & 0.162 & 0.691 & 1.972 & 0.89 \\
\hline Ministry of Labor and Social Affairs & 2.966 & 8.605 & 1.02 & 2.784 & 0.773 & 1.083 \\
\hline Supreme Council of Seminary & 6.624 & 4.444 & 0.162 & 3.033 & 0.291 & 0.985 \\
\hline Ministry of Culture and Islamic Guidance & 2.356 & 1.398 & 6.221 & 1.463 & 1.005 & 1.09 \\
\hline Ministry of Economic Affairs and Finance & 1.369 & 11.464 & 4.078 & 0.942 & 1.264 & 0.913 \\
\hline Islamic Republic of Iran Broadcasting & 0.762 & 1.865 & 2.474 & 1.271 & 1.704 & 1.206 \\
\hline Housing Foundation of Islamic Revolution & 0.219 & 3.323 & 0.162 & 1.474 & 1.972 & 1.377 \\
\hline Ministry of Justice & 2.974 & 0.839 & 3.248 & 2.177 & 0.698 & 1.09 \\
\hline Islamic Development Organization & 2.683 & 4.166 & 0.162 & 0.025 & 1.972 & 0.885 \\
\hline Cultural Heritage, Handcrafts and Tourism Organization & 1.06 & 3.929 & 0.162 & 0.908 & 1.084 & 1.111 \\
\hline Law Enforcement Force & 1.674 & 1.847 & 1.827 & 2.496 & 0.251 & 0.937 \\
\hline Ministry of Foreign Affairs & 0.172 & 0.191 & 0.667 & 1.169 & 1.972 & 1.83 \\
\hline Foundation of Martyrs and Veterans Affairs & 0.671 & 6.306 & 0.162 & 1.115 & 1.972 & 0.015 \\
\hline
\end{tabular}

\section{Table 4}

Positive and negative ideal solutions

\begin{tabular}{ccccccc}
\hline & PPA & GARAR & PCD & WRM & CD & CQ \\
\hline $\mathrm{v}_{\mathrm{j}}^{+}$ & 6.624 & 11.464 & 0.162 & 3.033 & 0.251 & 1.83 \\
$\mathrm{v}_{\mathrm{j}}^{-}$ & 0.172 & 0.191 & 17.403 & 0.025 & 1.972 & 0.015 \\
\hline
\end{tabular}

Eventually, by calculating the values of distance from the positives and negatives ideal solutions, the values of $\mathrm{d}+, \mathrm{d}-$ and $\mathrm{CL}$ can be calculated for each alternative which are the ranking of each administration agency's performance. The values are given in the Table 5. Considering the TOPSIS method, the Ministry of Labor and Social Affairs, The Supreme Council of Seminary, and The Ministry of Economic Affairs and Finance, respectively, have gained the first, second and third performance ranking.

\subsection{The governmental administration agencies ranking using GRA method}

According to the Table 1 which is considered as the decision matrix for the GRA method, the values of $X_{i j}$ for the more the better indicators are calculated using the Eq. (15) and the less the better indicators are calculated using the Eq. (16). Then the value of the coefficient of gray relationship as well as $\Delta$ is calculated for each alternative. The values of these coefficients for governmental administration agencies for each of the indicators are given in Table 6. 
Table 5

Final ranking of the governmental administration agencies in TOPSIS method

\begin{tabular}{|c|c|c|c|c|}
\hline Governmental Administration Agencies & $\mathrm{d}^{+}$ & $\mathrm{d}^{-}$ & $\mathrm{CL}$ & Rank \\
\hline Ministry of Industries and Mine & 18.842 & 6.305 & 0.251 & 26 \\
\hline Ministry of Agriculture Jihad & 12.591 & 9.715 & 0.436 & 24 \\
\hline Ministry of Sports and Youth & 10.613 & 13.784 & 0.565 & 14 \\
\hline Ministry of Interior & 9.668 & 14.813 & 0.605 & 11 \\
\hline Ministry of Science, Research and Technology & 10.221 & 13.321 & 0.566 & 13 \\
\hline Ministry of Health and Medical Education & 8.933 & 14.066 & 0.612 & 10 \\
\hline Ministry of Housing and Urban Development & 11.537 & 13.066 & 0.531 & 20 \\
\hline Ministry of Roads and Transportation & 10.634 & 13.225 & 0.554 & 18 \\
\hline Ministry of Education & 11.749 & 13.516 & 0.535 & 19 \\
\hline Ministry of Energy & 12.666 & 12.862 & 0.504 & 22 \\
\hline Ministry of Petroleum & 14.936 & 8.674 & 0.367 & 25 \\
\hline President Deputy Strategic Planning and Control & 7.566 & 15.869 & 0.677 & 6 \\
\hline Ministry of Information and Communications Technology & 11.27 & 12.638 & 0.529 & 21 \\
\hline Ministry of Welfare and Social Security & 8.007 & 18.844 & 0.702 & 4 \\
\hline Ministry of Labor and Social Affairs & 4.816 & 18.9 & 0.797 & 1 \\
\hline Supreme Council of Seminary & 7.071 & 19.23 & 0.731 & 2 \\
\hline Ministry of Culture and Islamic Guidance & 12.643 & 11.637 & 0.479 & 23 \\
\hline Ministry of Economic Affairs and Finance & 7.014 & 17.556 & 0.715 & 3 \\
\hline Islamic Republic of Iran Broadcasting & 11.725 & 15.135 & 0.563 & 15 \\
\hline Housing Foundation of Islamic Revolution & 10.626 & 17.636 & 0.624 & 9 \\
\hline Ministry of Justice & 11.714 & 14.698 & 0.556 & 17 \\
\hline Islamic Development Organization & 9.039 & 17.892 & 0.664 & 7 \\
\hline Cultural Heritage, Handcrafts and Tourism Organization & 9.668 & 17.742 & 0.647 & 8 \\
\hline Law Enforcement Force & 10.993 & 16.048 & 0.593 & 12 \\
\hline Ministry of Foreign Affairs & 13.245 & 16.873 & 0.56 & 16 \\
\hline Foundation of Martyrs and Veterans Affairs & 8.485 & 18.333 & 0.684 & 5 \\
\hline
\end{tabular}

Table 6

The Gray correlation coefficient for governmental administration agencies

\begin{tabular}{lcccccc}
\hline Governmental Administration Agencies & PPA & GARAR & PCD & WRM & CD & CQ \\
\hline Ministry of Industries and Mine & 0.683 & 0.726 & 0.333 & 0.919 & 0.430 & 0.847 \\
Ministry of Agriculture Jihad & 0.704 & 0.669 & 0.371 & 0.887 & 0.346 & 0.835 \\
Ministry of Sports and Youth & 0.902 & 0.613 & 0.400 & 0.975 & 0.365 & 0.812 \\
Ministry of Interior & 0.720 & 0.654 & 0.420 & 0.731 & 0.375 & 0.863 \\
Ministry of Science, Research and Technology & 0.723 & 0.654 & 0.401 & 0.852 & 0.413 & 0.818 \\
Ministry of Health and Medical Education & 0.681 & 0.727 & 0.406 & 0.777 & 0.394 & 0.823 \\
Ministry of Housing and Urban Development & 0.650 & 0.604 & 0.402 & 0.909 & 0.409 & 0.848 \\
Ministry of Roads and Transportation & 0.574 & 0.682 & 0.401 & 0.912 & 0.398 & 0.829 \\
Ministry of Education & 0.623 & 0.595 & 0.410 & 0.838 & 0.334 & 0.811 \\
Ministry of Energy & 0.544 & 0.577 & 0.402 & 0.930 & 0.380 & 0.876 \\
Ministry of Petroleum & 0.769 & 0.539 & 0.366 & 0.902 & 0.343 & 0.854 \\
President Deputy Strategic Planning and Control & 0.691 & 0.783 & 0.423 & 0.647 & 0.333 & 0.872 \\
Ministry of Information and Communications Technology & 0.583 & 0.660 & 0.398 & 0.816 & 0.333 & 0.833 \\
Ministry of Welfare and Social Security & 1.000 & 0.683 & 0.500 & 0.635 & 0.333 & 0.750 \\
Ministry of Labor and Social Affairs & 0.717 & 0.867 & 0.463 & 0.956 & 0.413 & 0.797 \\
Supreme Council of Seminary & 1.000 & 0.698 & 0.500 & 1.000 & 0.490 & 0.773 \\
Ministry of Culture and Islamic Guidance & 0.675 & 0.572 & 0.391 & 0.749 & 0.391 & 0.799 \\
Ministry of Economic Affairs and Finance & 0.606 & 1.000 & 0.412 & 0.672 & 0.372 & 0.756 \\
Islamic Republic of Iran Broadcasting & 0.559 & 0.593 & 0.433 & 0.720 & 0.346 & 0.829 \\
Housing Foundation of Islamic Revolution & 0.506 & 0.654 & 0.500 & 0.750 & 0.333 & 0.873 \\
Ministry of Justice & 0.718 & 0.544 & 0.422 & 0.856 & 0.422 & 0.799 \\
\hline Islamic Development Organization & 0.698 & 0.687 & 0.500 & 0.500 & 0.333 & 0.749 \\
Cultural Heritage, Handcrafts and Tourism Organization & 0.583 & 0.678 & 0.500 & 0.668 & 0.385 & 0.805 \\
Law Enforcement Force & 0.628 & 0.593 & 0.444 & 0.907 & 0.500 & 0.762 \\
\hline Ministry of Foreign Affairs & 0.500 & 0.500 & 0.474 & 0.706 & 0.333 & 1.000 \\
Foundation of Martyrs and Veterans Affairs & 0.552 & 0.771 & 0.500 & 0.698 & 0.333 & 0.500 \\
\hline
\end{tabular}

Using the calculated weights and the Eq. (5), the ranking of Gray relationship for each governmental administration agency is calculated and given in Table 7. The results indicate that based on the Gray Relational Analysis method, The Supreme Council of Seminary, The Ministry of Labor and Social Affairs, and the Ministry of Welfare and Social Security respectively have gained the first, second and third rankings. 
Table 7

Administrative agency of Gray relation rank

\begin{tabular}{lcc}
\hline Governmental Administration Agencies & Gray Relation Rank & Final Rank \\
\hline Ministry of Industries and Mine & 0.564 & 17 \\
Ministry of Agriculture Jihad & 0.564 & 16 \\
Ministry of Sports and Youth & 0.613 & 4 \\
Ministry of Interior & 0.572 & 11 \\
Ministry of Science, Research and Technology & 0.578 & 6 \\
Ministry of Health and Medical Education & 0.574 & 9 \\
Ministry of Housing and Urban Development & 0.565 & 14 \\
Ministry of Roads and Transportation & 0.561 & 18 \\
Ministry of Education & 0.546 & 21 \\
Ministry of Energy & 0.543 & 22 \\
Ministry of Petroleum & 0.556 & 20 \\
President Deputy Strategic Planning and Control & 0.576 & 8 \\
Ministry of Information and Communications Technology & 0.543 & 23 \\
Ministry of Welfare and Social Security & 0.639 & $\mathbf{3}$ \\
Ministry of Labor and Social Affairs & 0.645 & $\underline{\mathbf{2}}$ \\
Supreme Council of Seminary & 0.695 & $\underline{\mathbf{1}}$ \\
Ministry of Culture and Islamic Guidance & 0.538 & 24 \\
Ministry of Economic Affairs and Finance & 0.588 & 5 \\
Islamic Republic of Iran Broadcasting & 0.532 & 26 \\
Housing Foundation of Islamic Revolution & 0.565 & 15 \\
Ministry of Justice & 0.568 & 13 \\
Islamic Development Organization & 0.570 & 12 \\
Cultural Heritage, Handcrafts and Tourism Organization & 0.573 & 10 \\
Law Enforcement Force & 0.577 & 7 \\
Ministry of Foreign Affairs & 0.533 & 25 \\
\hline Foundation of Martyrs and Veterans Affairs & 0.561 & 19 \\
\hline
\end{tabular}

\section{Conclusions}

In this article, the application of multiple criteria decision approach for the evaluation of national civil development projects has been discussed. The results obtained from the two methods of the analysis of GRA and TOPSIS were somewhat different, because the gray system theory was used to solve obscure problems and discrete data and issues that have incomplete information. This theory uses relatively less information and results in a satisfactory output to create the variations. However, the TOPSIS method is a strong technique to prioritize the alternatives regarding their proximity to the ideal solution in such a way that the selected alternative must have the shortest distance from the ideal solution and the longest distance from the dysfunctional solution. Since the bases of these methods are different, the differences in the final results of the evaluation are justified. The results indicate that using the TOPSIS method, the Ministry of Labor and Social Affairs, the Supreme Council of Seminary and the Ministry of Economic Affairs and Financial, and using the GRA method, the Supreme Council of Seminary, the Ministry of Labor and Social Affairs and the Ministry of Welfare and Social Security, respectively have gained the highest ranking in performance. In the supervision report for national civil development projects, the governmental administration agencies were ranked using the Analytic Hierarchy Process (AHP). The results of the report indicate the Ministry of Industries and Mines, the Ministry of Agriculture Jihad and the Ministry of Sports and Youth respectively had gained the highest ranking. Whereas using the TOPSIS method, the Ministry of Industry and Mines, was ranked twenty six, and using the Gray Relational Analysis method, this ministry was ranked the seventeenth. The AHP method subjectively ranks the alternatives and does not benefit from the data obtained from the system; while the methods presented in this study, use objective data for both weighting and ratings of the administration agencies. Evidently, the more the actual data are used in the ranking process, the more valid the outcomes will be. It is recommended to carry out the evaluation of national projects based on technical indicators considered in the Institution of Presidency as well as other sustainable development indicators. For this purpose it is required that the Department of Planning collect the necessary data for 
each administration agency. The employment of comprehensive evaluation criteria can offer macrolevel decision makers a proper understanding of the various aspects of project implementations.

\section{References}

Deng, J. L. (1989). Introduction to grey system theory. The Journal of Grey System, 1(1), 1-24.

Ju-Long, D. (1982). Control problems of grey systems. Systems \& Control Letters, 1(5), 288-294.

Ebrahimnejad, S., Mousavi, S. M., \& Mojtahedi, S. M. H. (2008, September). A model for risk evaluation in construction projects based on fuzzy MADM. In Management of Innovation and Technology, 2008. ICMIT 2008. 4th IEEE International Conference on (pp. 305-310). IEEE.

Enea, M., \& Piazza, T. (2004). Project selection by constrained fuzzy AHP.Fuzzy optimization and decision making, 3(1), 39-62.

Huang, C. Y., Shyu, J. Z., \& Tzeng, G. H. (2007). Reconfiguring the innovation policy portfolios for Taiwan's SIP Mall industry. Technovation,27(12), 744-765.

Lu, I. J., Lin, S. J., \& Lewis, C. (2008). Grey relation analysis of motor vehicular energy consumption in Taiwan. Energy Policy, 36(7), 2556-2561.

Mohamadi, A., \& shojaei, P. (2011). Determining gas pipeline optimum route by using integrated FAHP/GRA model. Australian Journal of Business and Management Research, 1(3), 75-88.

Mohamadi, A., shojaei, P., \& Arabi, A. (2012). Determining the optimum route of gas pipeline by environmental quantitative approach case: Fars gas company. International Journal of Business and Management Tomorrow, 2(2), 1-7.

Opricovic, S., (1998). Multicriteria Optimization of Civil Engineering Systems. Faculty of Civil Engineering, Belgrade.

Oztaysi, B. (2014). A decision model for information technology selection using AHP integrated TOPSIS-Grey: The case of content management systems. Knowledge-Based Systems, 70(1), 44-54.

Piltan, M., \& Sowlati, T. (2016). A multi-criteria decision support model for evaluating the performance of partnerships. Expert Systems with Applications, 45, 373-384

Pophali, G. R., Chelani, A. B., \& Dhodapkar, R. S. (2011). Optimal selection of full scale tannery effluent treatment alternative using integrated AHP and GRA approach. Expert Systems with Applications, 38(9), 10889-10895.

President Deputy of Strategic Planning and Control (2013). Supervision Report of National Civil Development Projects in 2012. Tehran, Tehran: President Deputy of Strategic Planning and Control.

Tseng, P.Yi., Feng, C. M., \& Lin F.Y. (2003). The analysis of human and vehicle factors for Taiwan freeway traffic accidents. Journal of the Eastern Asia Society for Transportation Studies, 5(1), 2470-2482.

Tuysuz, F., \& Kahraman, C. (2006). Project risk evaluation using a fuzzy AHP: An application to information technology projects. International Journal of Intelligent Systems, 21(6), 559-584.

Tzeng, G.H., \& Teng, J.Y. (2007). Transportation project selection with fuzzy multiobjectives. Transportation Planning and Technology, 17(2), 91-112.

Uygun, Ö., \& Dede, A. (2016). Performance evaluation of green supply chain management using integrated fuzzy multi-criteria decision making techniques. Computers \& Industrial Engineering.

Wang, P., Zhu, Z., \& Wang, Y. (2016). A novel hybrid MCDM model combining the SAW, TOPSIS and GRA methods based on experimental design. Information Sciences, 345, 27-45.

Wang, Z. X., \& Wang, Y. Y. (2014). Evaluation of the provincial competitiveness of the Chinese hightech industry using an improved TOPSIS method. Expert Systems with Applications, 41(6), 28242831.

Ye, S., \& Tiong, R. (2000). NPV-at-Risk method in infrastructure project investment evaluation. Journal of Constraint Engineering Management, 126 (3), 227-233.

Zavadskas, E. K., Vilutienė, T., Turskis, Z., \& Šaparauskas, J. (2014). Multi-criteria analysis of Projects' performance in construction. Archives of Civil and Mechanical Engineering, 14(1), 114121. 